\title{
Papers
}

\section{Examination of instruments used to rate quality of health information on the internet: chronicle of a voyage with an unclear destination}

Anna Gagliardi, Alejandro R Jadad

\begin{abstract}
Objective This study updates work published in 1998, which found that of 47 rating instruments appearing on websites offering health information, 14 described how they were developed, five provided instructions for use, and none reported the interobserver reliability and construct validity of the measurements. Design All rating instrument sites noted in the original study were visited to ascertain whether they were still operating. New rating instruments were identified by duplicating and enhancing the comprehensive search of the internet and the medical and information science literature used in the previous study. Eligible instruments were evaluated as in the original study.

Results 98 instruments used to assess the quality of websites in the past five years were identified. Many of the rating instruments identified in the original study were no longer available. Of 51 newly identified rating instruments, only five provided some information by which they could be evaluated. As with the six sites identified in the original study that remained available, none of these five instruments seemed to have been validated.

Conclusions Many incompletely developed rating instruments continue to appear on websites providing health information, even when the organisations that gave rise to those instruments no longer exist. Many researchers, organisations, and website developers are exploring alternative ways of helping people to find and use high quality information available on the internet. Whether they are needed or sustainable and whether they make a difference remain to be shown.
\end{abstract}

\section{Introduction}

The quality of health information on the internet became a subject of interest to healthcare professionals, information specialists, and consumers of health care in the mid-1990s. Along with the rapid growth of healthcare websites came a number of initiatives, both academic and commercial, that generated criteria by which to ensure, judge, or denote the quality of websites offering health information. Some of these rating instruments took the form of logos resembling "awards" or "seals of approval" and appeared prominently on the websites on which they were bestowed.

In 1997 we undertook a review of "award-like" internet rating instruments in an effort to assess their reliability and validity. ${ }^{1}$ We hypothesised that if the rating instruments were flawed they might influence healthcare providers or consumers relying on them as indicators of accurate information. Instruments were eligible for review if they had been used at least once to categorise a website offering health information and revealed the rating criteria by which they did so. The rating instruments were evaluated according to, firstly, a system for judging the rigour of the development of tools to assess the quality of randomised controlled trials ${ }^{2}$ and, secondly, whether their criteria included three indicators suggested as appropriate for judging the quality of website content. ${ }^{3}{ }^{4}$ These indicators were authorship (information about authors and their contributions, affiliations, and relevant credentials), attribution (listing of references or sources of content), and disclosure (a description of website ownership, sponsorship, underwriting, commercial funding arrangements, or potential conflicts of interest). These criteria were selected for use in the original study because they could be rated objectively.

Our original study found that of 47 rating instruments identified, 14 described how they were developed, five provided instructions for use, and none reported the interobserver reliability and construct validity of the measurements. The review showed that many incompletely developed instruments were being used to evaluate or draw attention to health information on the internet.

The purpose of this study is to update the previous review of award-like rating instruments for the evaluation of websites providing health information and to describe any changes that may have taken place in the development of websites offering health information to practitioners and consumers with respect to the quality of their content.

\section{Methods}

We visited the websites describing each of the rating instruments noted in the original study to ascertain whether they were still operating. If internet service was disrupted for technical reasons or if sites were not
See Education and debate $\mathrm{p} 606$

Graduate Department of Health Policy, Management and Evaluation, Faculty of Medicine, University of Toronto, Toronto, ON, Canada Anna Gagliardi senior research associate

Departments of Health Policy, Management and Evaluation, and Anaesthesia,

University Health Network, University of Toronto, Toronto ON, Canada

Alejandro R Jadad professor

Correspondence to: A R Jadad, Director, Centre for Global eHealth Innovation, University Health

Network, Toronto General Hospital, Fraser Elliott Building, 4th Floor, 190 Elizabeth Street, Toronto, ON M5G 2C4, Canada ajadad@uhnres. utoronto.ca

BMJ 2002;324:569-73 
Table 1 Summary of criteria for rating instruments

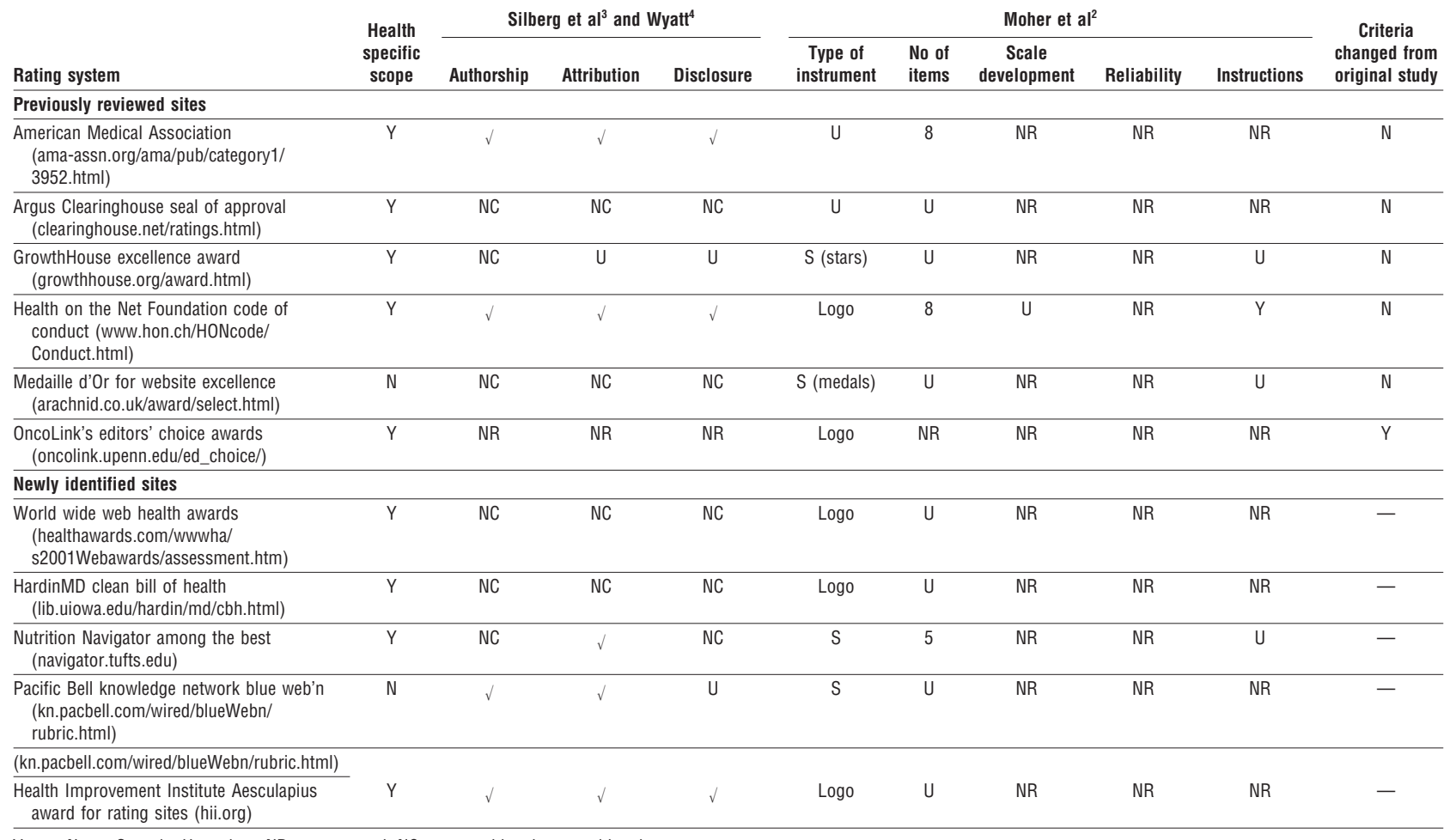

$\mathrm{Y}=\mathrm{yes} ; \mathrm{N}=$ no; $\mathrm{S}=$ scale; $\mathrm{U}=$ unclear; $\mathrm{NR}=$ not reported; NC=not considered; $\sqrt{ }=$ considered.

available on first visit, we attempted a connection on one further occasion.

The search strategies, inclusion and exclusion criteria, and techniques for data extraction were similar to those used in the original review. ${ }^{1}$ We used the following sources to identify new rating instruments:

- A search to 7 September 2001 of Medline, CINAHL, and HealthSTAR (from December 1997) using [(top or rat: or rank: or best) and (internet or web) and (quality or reliab: or valid:)]

- A search of the databases Information Science Abstracts, Library and Information Science Abstracts (1995 to September 2001), and Library Literature (1996 to September 2001) using [(rat: or rank: or top or best) and (internet or web or site) and (health:)]

- A search to September 2001 using the search engines Lycos (lycos.com), Excite (excite.com), Yahoo (yahoo.com), HotBot (hotbot.com), Infoseek (go.com), Looksmart (looksmart.com), and Google (google.com) with [(rate or rank or top or best) and (health)]. Open Text (opentext.com) and Magellan (magellan.com), which were used in the first study, no longer function as internet search engines

- A review of messages about rating instruments and the quality of health related websites posted to the Medical Library Association listserv medlib-1 (listservacsu.buffalo.edu/archives/medlib-l.html) and the Canadian Health Libraries Association listserv canmedlib-l (lists.mun.ca/archives/canmedlib.html)

- A search of the American Medical Informatics Association's 1998, 1999, 2000, and 2001 annual symposium programmes (www.amia.org) for mention of health information on the internet

- A search of the Journal of Medical Internet Research (September 1999 to September 2001) for mention of evaluations of the quality of health information on the internet (www.jmir.org)

- A search of the online archive of the magazine Internet World (www.internetworld.com) (January 2000 to September 2001) for mention of health information on the internet.

We also reviewed relevant articles referenced in identified studies and links available on identified websites. We did not search the discussion list Public Communication of Science and Technology, which was consulted in the original study.

We stopped searching for rating instruments on 22 September 2001. Rating instruments were eligible for inclusion in the review if it was possible to link from their award-like symbol to an available website describing the criteria used by an individual or organisation to judge the quality of websites on which the award was bestowed. We excluded rating instruments from review if they were used only to rate sites offering non-health information or did not provide any description of their rating criteria. In contrast to the initial study, we did not contact the developers of rating instruments to request information about their criteria if it was not publicly available on their website.

We identified the website, group, or organisation that developed each eligible rating instrument, along with its web address. The two authors independently evaluated each rating instrument according to its validity (number of items in the instrument, availability of rating instructions, information on the development of rating criteria, and evaluation of interobserver reliability) and incorporation of the proposed criteria for evaluation of internet sites: authorship, attribution, and disclosure. ${ }^{2-4}$ 


\section{Results}

Fourteen rating instruments identified in the original study provided a description of their rating criteria and were therefore eligible for review. Six of these continued to function. Of the remaining eight instruments, four were no longer in operation and four had converted to a directory format. Table 1 summarises the review of the six functioning instruments. Our evaluation of one of these instruments, OncoLink's editors' choice awards, differed from that in the original study because the organisation does not provide information about the instrument on its website.

Of the 33 rating instruments identified in the original study that were not eligible for review, three continued to function. These were Best Medical Resources on the Web (priory.com/other.htm), Dr Webster's website of the day (drWebster.com), and HealthSeek quality site award (healthseek.com). None of these rating instruments revealed its rating criteria, and they therefore remained ineligible for review. Of the remaining rating instrument websites, 10 were no longer in operation, five had been subsumed by or merged with another organisation and had a different name or purpose, and 15 still offered a website but did not function as a rating instrument

We newly identified 51 rating instruments. Eleven of these were identified as award-like symbols on a website offering health information, but the website of the organisation from which they originated was no longer operating (table 2). Of the remaining 40 rating instruments, 35 were associated with an active website but did not reveal the criteria by which they judge websites and were ineligible for evaluation (table 3). Five award sites discussed their evaluation criteria and were assessed (table 1). Although three of these five rating instruments exhibited one or more of the characteristics of authorship, attribution, and disclosure, none reported on the reliability and validity of the measurements or provided instructions on how to obtain the ratings.

\section{Discussion}

During the past five years, we have identified a total of 98 different rating instruments that have been used to assess the quality of websites. Many of the rating instruments identified in the original study were no longer available. Fifty one additional rating instruments have been developed since 1997, and many of these had also stopped functioning. Of 51 newly identified rating instruments, only five provided some information by which they could be evaluated. As with the six rating instrument sites identified in the original study that remained available, none of these seems to have been validated. Many incompletely developed rating instruments continue to appear on websites providing health information, even when the organisations that gave rise to them no longer exist. Surprisingly, many of these rating instruments, of questionable utility and without association to an operable entity, are featured on the US Department of Health and Human Services Healthfinder website (www.healthfinder.gov/aboutus/ awards.htm), which uses a detailed and rigorous selection process for the development of its own content.
Table 2 Newly identified award sites not available

\begin{tabular}{ll} 
Rating instrument & Address \\
\hline Computer Currents interactive link of the week award & currents.net \\
\hline E-Medic Online medical award for excellence & emediconline.com \\
\hline Eye on the Web selected site award & eyeontheWeb.com \\
\hline Family Education Resource Network top family site & familytrack.com \\
\hline Internet Voyager 5-star site & internetvoyager.com \\
\hline Lesbianmoms and Gaydads site award winner & lesbianmoms.org \\
\hline Nicecom nicelinks & nicecom.com \\
\hline Smart Computing top website & smartcomputing.com \\
\hline Starting Point choice award & www.stpt.com \\
\hline USA Today hot site & www.usatoday.com \\
\hline WebNet web rating & www.Webratings.net \\
\hline
\end{tabular}

Table 3 Newly identified available award sites not eligible for review

\begin{tabular}{|c|c|}
\hline Rating instrument & Address \\
\hline 100hot & 100hot.com \\
\hline Achoo site of the week & achoo.com \\
\hline Aids Awareness recognition award & $\begin{array}{l}\text { www.geocities.com/WestHollywood/3390/ } \\
\text { AARAWARD.HTM }\end{array}$ \\
\hline Awesome Library editor's choice & awesomelibrary.org \\
\hline Beagle WebPick & biomednet.com \\
\hline BioMed Link & links.bmn.com \\
\hline Brill's Content best of the web & inside.com \\
\hline $\begin{array}{l}\text { Complete idiot's guide to online health and } \\
\text { fitness }\end{array}$ & fitnesslink.com \\
\hline Fitness Partner Connection champion websites & $\begin{array}{l}\text { primusWeb.com/fitnesspartner/library/features/ } \\
\text { tour0198.htm }\end{array}$ \\
\hline Forbes best of the web & forbes.com/bow/ \\
\hline FSPronet site of the week & fspronet.com \\
\hline Go Network website award & go.com \\
\hline Golden Web Awards & goldenWebawards.com \\
\hline GoTo.com editor's choice award & goto.com \\
\hline GovSpot spotlight award & govspot.com \\
\hline Hammer award & surgeongeneral.gov/todo/pressreleases/HammerRel2.htm \\
\hline Health Launchbase & health.launchbase.net \\
\hline HealthLinks selects site & healthlinks.net \\
\hline HotSheet featured site & hotsheet.com \\
\hline Library Spot site of the month & libraryspot.com/refsiteofmonth0499.htm \\
\hline Links2Go key resource award & links2go.com/award/Hospice \\
\hline Mac's Picks recommended websites & 2x2.co.nz/picks/ \\
\hline MedExplorer top rated category listings & medexplorer.com/toprated.dbm \\
\hline Popular Science 50 best of the web & popsci.com \\
\hline Rainbow award & www.gayamerica.com/awards/ \\
\hline RE Library pure gold award & relibrary.com \\
\hline Suite 101 top 5 website & suite101.com \\
\hline the1000.com webmaster select site & the1000.com \\
\hline thegoodWebguide.co.uk recommended site & thegoodWebguide.co.uk \\
\hline Third Age 701 special sites & thirdage.com \\
\hline Top 100 health sites & www.health-top100.com/ \\
\hline Top 100 network & 100.com/Top/Health \\
\hline Web100 & Web100.com/listings/health.html \\
\hline World hottest 100 health websites & worldhot.com \\
\hline Yahoo! Internet Life's 100 best sites for 2001 & zdnet.com/techlife/ \\
\hline
\end{tabular}

Our initial questions remain unanswered. Is it desirable or necessary to assess the quality of health information on the internet? If so, is it an achievable goal given that quality is a construct for which we have no gold standard? Some effort has been made to identify whether the presence of rating instrument awards influences consumers of health information, ${ }^{5}$ but whether validated rating instruments would have an impact on the competence, performance, behaviour, and health outcomes of those who use them remains unclear.

Our search of the literature and the internet revealed that a large number of researchers, organisa- 


\begin{tabular}{|c|c|c|c|}
\hline Organisation & Product & Description & Cost associated with use \\
\hline $\begin{array}{l}\text { US Department of Health and Human } \\
\text { Services (www.healthfinder.com) }\end{array}$ & Healthfinder & $\begin{array}{l}\text { Directory of health resources selected } \\
\text { according to explicit criteria }\end{array}$ & - \\
\hline $\begin{array}{l}\text { Government of Australia } \\
\text { (www.healthinsite.gov.au) }\end{array}$ & HealthInsite & $\begin{array}{l}\text { Directory of health resources selected } \\
\text { according to explicit criteria }\end{array}$ & - \\
\hline National Health Service (nhsdirect.nhs.uk) & NHS Direct Online & $\begin{array}{l}\text { Directory of health resources selected } \\
\text { according to DISCERN criteria }\end{array}$ & - \\
\hline $\begin{array}{l}\text { Health Summit Working Group } \\
\text { (hitiWeb.mitretek.org/hswg/) }\end{array}$ & Information quality tool & $\begin{array}{l}21 \text { criteria by which consumers can } \\
\text { evaluate websites }\end{array}$ & - \\
\hline Health on the Net Foundation (www.hon.ch) & HON code of conduct & $\begin{array}{l}8 \text { criteria to guide development of } \\
\text { website content }\end{array}$ & - \\
\hline $\begin{array}{r}\text { Internet Healthcare Coalition } \\
\text { (www.ihealthcoalition.org) }\end{array}$ & e-Health code of ethics & $\begin{array}{l}14 \text { criteria by which consumers can } \\
\text { evaluate websites }\end{array}$ & - \\
\hline DISCERN on the Internet (discern.org.uk) & Questionnaire and user manual & $\begin{array}{l}16 \text { criteria by which consumers can } \\
\text { evaluate websites }\end{array}$ & - \\
\hline Hi-Ethics Principles (www.hiethics.com) & E-Health seal & $\begin{array}{l}14 \text { criteria to guide development of } \\
\text { website content }\end{array}$ & $\$ 20000$ annual membership fee \\
\hline $\begin{array}{l}\text { American Accreditation HealthCare } \\
\text { Commission (www.urac.org) }\end{array}$ & $\begin{array}{l}\text { Health website accreditation } \\
\text { programme }\end{array}$ & $\begin{array}{l}53 \text { criteria to guide development of } \\
\text { website content }\end{array}$ & $\begin{array}{l}\text { Sliding scale based on revenue ranges } \\
\text { from } \$ 3799 \text { to } \$ 12249\end{array}$ \\
\hline TRUSTe (www.truste.org) & $\begin{array}{l}\text { Online seal ("trustmark") and } \\
\text { mechanism for resolution of } \\
\text { disputes }\end{array}$ & $\begin{array}{l}\text { For consumers purchasing on line or } \\
\text { providing personal information }\end{array}$ & $\begin{array}{l}\text { Sliding scale based on revenue and } \\
\text { number of brands ranges from } \$ 399 \text { to } \\
\$ 25000 \text { annually }\end{array}$ \\
\hline $\begin{array}{l}\text { Council of Better Business Bureaus } \\
\text { (bbbonline.org) }\end{array}$ & $\begin{array}{l}\text { Reliability seal and privacy seal } \\
\text { programme plus mechanism for } \\
\text { resolution of disputes }\end{array}$ & $\begin{array}{l}\text { Online reliability standards to guide } \\
\text { truthful advertising }\end{array}$ & $\begin{array}{l}\text { Membership of Better Business Bureau; } \\
\text { fees not disclosed. }\end{array}$ \\
\hline
\end{tabular}

tions, and website developers are exploring alternative ways to help people find and use high quality information available on the internet. Many reviews of healthcare information on the internet have been conducted, overall and for specific diseases or conditions. ${ }^{6-12}$ Examination of over 90 reviews concluded that the validity of health information available on websites is highly variable across different diseases and populations, and is in many cases potentially misleading or harmful (G Eysenbach, personal communication, 2001). Several organisations, including government and non-profit entities, have developed criteria by which to organise and identify valid health information (table 4). Other groups, such as the OMNI Advisory Group for Evaluation Criteria (omni.ac.uk) and the Collaboration for Critical Appraisal of Information on the Net (www.medcertain.org), are refining technical mechanisms by which users of the internet can easily locate quality health information in a transparent manner based on evaluative metainformation labelling and indexing. ${ }^{13-15}$ The impact of these efforts remains unclear.

More recently, a European project recommended the accreditation of healthcare related software, telemedicine, and internet sites. ${ }^{16}$ They suggested a mechanism similar to the marking of electrical goods for software, that national regulatory bodies should be identified for telemedicine, and that a European certification of integrity scheme should be developed for websites. Citing the many impediments to voluntary quality assurance for websites, the authors suggest the development of criteria, modifiable according to the needs of special interest groups, that would be used by accredited agencies to self label conforming websites (not only those offering health information) with a EuroSeal. Monitoring of integrity would be ongoing through cryptographic techniques.

In conclusion, our updated study shows that award systems based on non-validated rating instruments continue to be produced but that most stop functioning soon after their release. Alternative strategies are now flourishing, and whether they are

\section{What is already known on this topic}

The rapid growth of healthcare websites in the 1990s was accompanied by initiatives to rate their quality, including award-like symbols on websites

A systematic review of the reliability and validity of such rating instruments, published in 1998, showed that they were incompletely developed

\section{What this study adds}

Few of the rating instruments identified in 1998 remain functional; 51 new instruments were identified

Of the 51 newly identified instruments, 11 were not functional, 35 were available but provided no information, and five provided information but were not validated

Many researchers, organisations, and website developers are exploring alternative ways of helping people to find high quality information on the internet

valid, needed, or sustainable and whether they make a difference is the subject of further research.

Contributors: AG conducted the searches, extracted relevant data, evaluated eligible instruments, and drafted the manuscript. ARJ developed the idea for the original study, independently evaluated eligible instruments, edited the manuscript, and is guarantor for this paper.

Funding: ARJ was supported by funds from the University Health Network, the Rose Family Chair in Supportive Care, and a Premier's Research Excellence Award from the Ministry of Energy, Science and Technology of Ontario.

Competing interests: None declared.

1 Jadad AR, Gagliardi A. Rating health information on the internet: navigating to knowledge or to Babel? JAMA 1998;279:611-4. 
2 Moher D, Jadad AR, Nichol G, Penman M, Tugwell P, Walsh S. Assessing the quality of randomized controlled trials: an annotated bibliography. Control Clin Trials 1995;16:62-73.

3 Silberg WM, Lundberg GD, Musacchio RA. Assessing, controlling and assuring the quality of medical information on the internet. JAMA 1997;277:1244-5.

4 Wyatt JC. Measuring quality and impact of the world wide web [commentary]. BMJ 1997;314:1879-81.

5 Shon J, Marshall J, Musen MA. The impact of displayed awards on the credibility and retention of web site information. Proc AMIA Symp 2000:794-8.

6 Berland GK, Elliott MN, Morales LS, Algazy JI, Kravitz RL, Broder MS, et al. Health information on the internet: accessibility, quality, and readability in English and Spanish. JAMA 2001:285:2612-21.

7 Li L, Irvin E, Guzman J, Bombardier C. Surfing for back pain patients: the nature and quality of back pain information on the internet. Spine 2001;26:545-7.

8 Suarez-Almazor ME, Kendall CJ, Dorgan M. Surfing the net-information on the world wide web for persons with arthritis: patient empowerment or patient deceit? J Rheumatol 2001;28:185-91.
9 Impiccatore P, Pandolfini C, Casella N, Bonati M. Reliability of health information for the public on the world wide web: systemic survey of advice on managing fever in children at home. BMJ 1997;314:1875-9.

10 Griffiths KM, Christensen H. Quality of web based information on treatment of depression: cross sectional survey. BMJ 2000;321:1511-5.

11 Abbott VP. Web page quality: can we measure it and what do we find? A report of exploratory findings. J Public Health Med 2000;22:191-7.

12 Tamm EP, Raval BK, Huynh PT. Evaluation of the quality of self-education mammography material available for patients on the internet. Acad Radiol 2000;7:137-41.

13 Eysenbach G, Diepgen TL. Towards quality management of medical information on the internet: evaluation, labelling, and filtering of information. BMJ 1998;317:1496-500.

14 Eysenbach G, Diepgen TL. Labeling and filtering of medical information on the internet. Methods Inf Med 1999;38:80-8

15 Price SL, Hersh WR. Filtering web pages for quality indicators: an empirical approach to finding high quality consumer health information on the world wide web. Proc AMIA Symp 1999:911-5.

16 Rigby M, Forsstrom J, Roberts R, Wyatt J. Verifying quality and safety in health informatics services. BMJ 2001;323:552-6.

\section{How do consumers search for and appraise health information on the world wide web? Qualitative study using focus groups, usability tests, and in-depth interviews}

Gunther Eysenbach, Christian Köhler

\begin{abstract}
Objectives To describe techniques for retrieval and appraisal used by consumers when they search for health information on the internet.

Design Qualitative study using focus groups, naturalistic observation of consumers searching the world wide web in a usability laboratory, and in-depth interviews.

Participants A total of 21 users of the internet participated in three focus group sessions. 17 participants were given a series of health questions and observed in a usability laboratory setting while retrieving health information from the web; this was followed by in-depth interviews.

Setting Heidelberg, Germany.

Results Although their search technique was often suboptimal, internet users successfully found health information to answer questions in an average of 5 minutes 42 seconds (median 4 minutes 18 seconds) per question. Participants in focus groups said that when assessing the credibility of a website they primarily looked for the source, a professional design, a scientific or official touch, language, and ease of use. However, in the observational study, no participants checked any "about us" sections of websites, disclaimers, or disclosure statements. In the post-search interviews, it emerged that very few participants had noticed and remembered which websites they had retrieved information from.

Conclusions Further observational studies are needed to design and evaluate educational and technological innovations for guiding consumers to high quality health information on the web.
\end{abstract}

\section{Introduction}

Little is known about how consumers retrieve and assess health information on the world wide web. Some surveys have elicited data by using semistructured questionnaires or focus groups, ${ }^{1-3}$ but little (if any) unobtrusive observational research has been done to explore how consumers are actually surfing the web. Although several criteria for quality of health websites have been proposed-including disclosure of site owners, authors, and update cycle ${ }^{4}$-little or nothing is known about whether and to what degree such markers are recognised or even looked at by consumers or what other credibility markers consumers are looking for. We aimed to obtain qualitative and semiquantitative data to generate some hypotheses on how consumers might search for and appraise health information.

\section{Methods}

We used multiple methods of data collection that are commonly used in studies of human-computer interactions, ${ }^{6}$ combining focus groups, ${ }^{7}$ naturalistic observation of consumers searching the internet, and post-search in-depth interviews. Two researchers independently analysed transcripts by using N5 (NUD*IST 5.0; QSR International, Melbourne) with the grounded theory approach. ${ }^{8}$

Participants in the focus groups and the observational study were mostly healthy volunteers recruited through newspaper advertisements seeking people who had already searched for health information on the web. We selected them on a first come first served basis.

\section{Focus groups}

We held three focus group sessions with 6-8 participants each (21 participants in total: five men, 16 women; mean and median age 37 , range $19-71$ years) in March 2001. Self reported internet experience of the participants ranged from 17 to 84 months (mean 46 months; median 42 months). Each session was facilitated by a skilled moderator and lasted about two
Unit for

Cybermedicine and

eHealth,

Department of

Clinical Social

Medicine,

University of

Heidelberg,

Bergheimer Str 58

69115 Heidelberg,

Germany

Gunther Eysenbach

senior researcher

Christian Köhler

researcher

Correspondence to: G Eysenbach ey@yi.com

BMJ 2002;324:573-7 